\title{
Obstetric Fistula: Existing Challenge of Developing Countries
}

\section{Pramod Kattel}

Department of Obstetrics and Gynecology, B. P. SMRITI Hospital, Basundhara, Kathmandu, Nepal

DOI: http://dx.doi.org/10.3126/njog.v13i2.21710

\begin{abstract}
Developing countries are the home ground of obstetric fistula. It is usually the result of injury following childbirth or its consequences. The most common type of obstetric fistula is vesico-vaginal. Neglected obstructed labour is considered as the major etiology. Persistent leakage of urine is the most common presentation. It usually develops 3 to 14 days following childbirth. It degrades the quality of life of females. It may lead to medical, social, economic and psychological effects on reproductive age females. It is the marker to determine the quality of health system of any country. Proper use of partograph and timely intervention decreases its prevalence. History, examination and dye test are usually taken as main diagnostic tools in resource poor settings. It is a treatable condition at usual times. Social awareness regarding fistula is the need of developing countries. Drink, Dry and Drain are the key parameters of fistula repair success. Social rehabilitation following surgical repair is of prime importance.
\end{abstract}

Keywords: birth injuries, developing countries, fistula, vesicovaginal fistula.

\section{INTRODUCTION}

Obstetric fistula is the result of serious and tragic childbirth injury. Two million people in the world are suffering from obstetric fistula especially in developing countries of Asia, Sub-Saharan Africa, Arab, Latin America and the Caribbean region. ${ }^{1}$ About 50000 to 100000 new cases per year are added to the list. ${ }^{1,2}$ The estimated prevalence in developing countries is 1 to 3 per thousand deliveries. ${ }^{3}$

\section{DESCRIPTION}

Fistula is the abnormal connection between two or more epithelial surfaces. ${ }^{4}$ Obstetric fistula is the abnormal connection between birth canal and urinary system/ lower gastro-intestinal tract due to obstetric cause. ${ }^{3-6}$ The most common one is vesico-vaginal fistula (VVF) i.e. fistula between bladder and vagina. In developing countries more than $70 \%$ of fistulas are obstetric in origin. The common sites of obstetric fistula being midvaginal, juxtracervical or massive; reflecting obstetric origin. Obstetric fistula usually occur when prolonged obstructed labour is not attended on time due to unavailability of caesarean section (CS) or not being able to identify obstructed labour and waiting for labour to progress normally. ${ }^{1,3,5-10}$ The other causes being low quality CS. ${ }^{10}$ Obstructed labour may lead to grave consequences of feto-maternal morbidity and

\section{CORRESPONDENCE}

Dr Pramod Kattel

Department of Obstetrics and Gynecology, B. P. SMRITI

Hospital, Basundhara, Kathmandu, Nepal

Email: pramodkattel85@gmail.com

Phone: +977-9847088684 even mortality. ${ }^{6}$ Fetus may have poor Apgar score at delivery or may be delivered still birth whereas mother may die due to ruptured uterus or may bear the consequence of fistula if survived. ${ }^{3,5,6,9}$ She will remain in state of "walking dead". ${ }^{3}$ Patient presents with persistent leakage of urine or faecus through vagina. $^{3-6,8,9}$ In obstetric fistula, the symptom develop in early post partum period i.e. usually between 3 to 14 days. $^{7}$ Obstetric fistula may not take life but certainly will affect the quality of life adversely. It is a preventable entity and almost $80 \%$ to $90 \%$ of VVF cases are treated by simple vaginal surgeries. $1,5,7,8$ Treatment of fistula is initiated at any time it is noticed and success of treatment depends upon size and/or site of fistula and healthiness of tissue along with involvement of sphincter. ${ }^{4}$

Experienced surgeons along with dedicated fistula centres and first surgery increases the success rate of surgical repair in obstetric fistulas. ${ }^{5}$ Poor medical services, unawareness regarding treatment and sites of treatment make the situation worse as there are only few people getting involved on care of such devastating condition. ${ }^{9}$ Even though fistula client tries to remain healthy but the continuous leakage of urine makes the environment polluted which might be the reason behind being neglected from family and being out-casted from society. ${ }^{3,5,6,8,9}$ It has both immediate and long term consequences. There is always the risk of suffering from mental illness due to chronic nature of condition and paucity of treatment. The occurrence of fistula reflects the challenges of programs like safe motherhood. People staying with fistula signify the poor outreach of health care along with poor literacy 
status and poverty. ${ }^{8}$ It leads to physical, social, economic, political and psychological/emotional decline. ${ }^{3,5,9}$ Occurrence of fistula even leads to loss of job and makes poor people even poorer. ${ }^{9}$ She may have to live with tragedy of child loss or even get divorced and have to live isolated and shameful life. ${ }^{3,5,9}$ Contributors for fistula formation includes three delays of healthcare which are delay in seeking medical attention, delay in reaching medical facilities and delay in providing adequate care at health facilities. ${ }^{6}$

\section{RISK FACTORS AND ETIOLOGY}

There are different risk factors and etiologies for fistula formation some of which are early marriage, lack of proper education, poverty, absence of adequate family planning services at accessible sites, child bearing at young age, primiparity, big baby, mal-presentation like occipito-posterior position, contracted pelvis, malnutrition, untreated infections of genital tract, home delivery, health system failure i.e. lack of access to health facilities/lack of adequate trained manpower/lack of proper equipments, difficult/poor quality CS, ruptured uterus, breech extraction, caesarean hysterectomy, traditional practices (defibulation required for pharaonic circumcision), neglected prolonged obstructed labor, instrumental vaginal delivery by using Forceps/ ventouse, faulty repair of third or fourth degree tear, destructive delivery like craniotomy, symphysiotomy and complications of criminal abortion. ${ }^{3-6,8-10}$

\section{PRESENTATION}

Patient with obstetric fistula may present with one or more of the signs and symptoms of continuous urinary incontinence during both day and night, absence of sensation of bladder fullness, infrequent bladder fullness, cyclical hematuria during menstruation or menouria due to continence maintained at uterine isthmus, incontinence of liquid stool and flatus, pyrexia, frequent urinary tract infections (UTIs) and depression. ${ }^{3,4,8}$ There may be history of recent difficult delivery or pelvic surgery. ${ }^{4}$

\section{COMPLICATIONS}

Patients with obstetric fistula may develop complications on long run. They may present with adverse dermatological conditions of excoriations/ ulcerations of skin, rashes, skin infections, genitourinary abnormalities of urethral damage, bladder damage, vaginal stenosis/strictures or uterine scarring, rectal damage, sexual dysfunction, risk of being abused and being victim of gender based violence, secondary infertility, recurrent UTI, hydroureter, hydronephrosis, renal failure, weakness in leg, foot drop, obstetric palsy, and/or psychological problems including suicidal ideation/tendency. ${ }^{3,5,8,9}$

\section{PREVENTION}

Varied roles can be played by different stakeholders to prevent obstetric fistula. The measures that can be played are economic up-liftment of females and their families, delaying of first pregnancy to appropriate age, strictly following legal age at marriage and provision for punishment if violated with practical implementation, cessation of harmful traditional practices, easy and early access to health facilities, early identification of risk factors, maintaining partograph, provision of trained man-power to identify risks and prolonged/obstructed labor, facilitation of caesarean section at health facility or provision of timely referral with facilities for transportation, avoidance of prolonged or obstructed labor by active management and timely identification of problems and readiness for its solutions, precautions to be taken during CS in prolonged or obstructed labour (adequate bladder separation from uterus, high incision to be made on lower uterine segment, pushing fetus from vagina, keeping urethral catheter for 7 to 14 days, adequate hydration post-surgery with three to five litre of fluid per day), teaching pelvic floor exercises post-delivery with adequate follow up, timely detection of fistula so that even conservative measures helps to heal in minor cases preventing further surgical intervention and complications and promoting fistula awareness in society. $3,5,7$

\section{TREATMENT AND AIMS OF FISTULA REPAIR}

There are different modalities of fistula repair. Depending upon the size, mode of injury, involvement of sphincter, time of presentation, healthiness of tissue including scarring and previous attempts of repair; either conservative or surgical modes can be opted. In a nutshell surgery is the definitive treatment for obstetric fistula. ${ }^{4}$ The aim of fistula repair is to achieve good closer of fistulous tract and achieve continence along with restoration of normal sexual 
life including fertility. Fistula treatment also aims for ensuring safe obstetric care including delivery in future and re-integration of patient into the society for living with pride and dignity. 3,5

\section{PRINCIPLE OF FISTULA SURGERY}

Surgery is the main mode of fistula repair. In low resource settings, fistula is diagnosed based on history, examination and positive dye test. If tissue is healthy then immediate repair (within 24 to 48 hour) following diagnosis is attempted. During repair process, proper exposure of fistulous tract is needed for adequate tissue dissection and mobilization. ${ }^{4}$ Tissue handling should be done gently following which tension free layered closure (if possible) but water tight repair is done. ${ }^{3,4}$ Following fistula repair intra-operative and post surgical dye test should be negative. ${ }^{4}$ During post-operative care, principle of "3D's" are followed strictly which implies Drink (adequate hydration with three to five litre of fluid per day), Dry (catheterization for 7 to 28 days), and Drain (avoidance of kinking of catheter).,

\section{COMPLICATIONS FOLLOWING FISTULA REPAIR}

Fistula repair is not devoid of complications. If there is massive loss of tissue, it may cause repair of fistula challenging. At times even if fistula is repaired, there may be chance of breakdown of fistula. ${ }^{5,8}$ There may be chance of problem of incontinence as previous due to loss of sphincteric function (physiological failure) even though anatomical success is achieved. ${ }^{3,8}$ Bladder contracture may be noted and there is risk of increased post-voidal residual volume. ${ }^{5}$ There may be continuation or development of urinary complications of stress or urge urinary incontinence along with overactive bladder., ${ }^{3,5}$

\section{CHILDBIRTH POST-FISTULA REPAIR}

If patient with fistula repair becomes pregnant subsequently, they are advised to undergo elective CS as preferred mode of delivery.

\section{CHALLENGES}

Obstetric fistula has created challenge for developing countries. Though obstetric fistula is common in developing countries but skilled man-power (Fistula surgeons, dedicated nursing staffs and physiotherapists) and dedicated centres to treat the same are limited in the region. Lack of medical supplies and equipments along with lack of continuity of existing services add further challenges. From the patient perspectives, follow up of patient is poor. There is also lack of rehabilitation centres and reintegration of fistula patients into society is also of great challenge. ${ }^{5}$ It is one of the neglected parts on patient care. Women suffering from fistula do not have access to health facilities and even lack the knowledge that it is a treatable condition in majority of cases. The cost of care is also a challenge though in some developing countries they are performed on free following international donation but this information at most times does not reach to the needy people and the foreign support may not be sustainable. There is a large unmet need of treatment of obstetric fistula. There are about 100000 new cases per year in addition to two million pre-existing sufferers and only about 20000 surgeries are performed per year which justifies the increased challenge for developing countries. ${ }^{2,6,11}$

\section{CONCLUSIONS}

Obstetric fistula is seen as problem of developing countries. It is the result of untimely and mismanagement of labour in majority of cases. Though it usually does not cause mortality of patient directly but the morbidities that it creates have grave consequences and compel people to live with poor quality of life. Women have to live in isolation, shame and social stigma. Proper intra-partum follow up with partograph helps to decrease its incidence. Programs like safe motherhood should take this problem in account so that necessary steps to decrease the incidence can be adopted with trained health workers i.e. skilled birth attendants, facility for caesarean section or timely referral. It is both a preventable and treatable entity. Timely surgical closure of fistulous tract is the most effective treatment of obstetric fistula so that the patient can live a normal life as previous. Awareness regarding fistula needs to be made from grass-root level of society. Fistula camps should be organized to bring the affected women to health facilities for proper management. 


\section{REFERENCES}

1. UNFPA. Obstetric fistula. New York: United Nations Population Fund [Internet]. [updated 2018 Jun 27; cited 2018 Aug 30]. [Full Text]

2. WHO. 10 facts on obstetric fistula. Zeneva: World Health Organization [Internet]. [updated 2018 Jan; cited 2018 Aug 30]. [Full Text]

3. Polan ML, Sleemi A, Bedane MM, Lozo Svjetlana, Morgan MA. Obstetric fistula. In: Debas HT, Donkor P, Gawande A, Jamison DT, Kruk ME, Mock CN, editors. Essential surgery: Disease control priorities. 3rd ed. Washington DC: World Bank: 2015. Chapter 10. vol 1. [PubMed Full Text DOI Bookshelf ID]

4. Hoffman B, Schorge JO, Bradshaw KD, Halvorson LM, Schaffer JI, Corton MM. Genitourinary Fistula and Urethral Diverticulum. Williams Gynaecology. 3th ed. New York:Mc Graw Hill-Education; 2016. Chapter 26. p.577-88. [Full Text]

5. ICS Committees. Obstetric fistula in the developing world An introduction. International Continence Society [Internet]. [Cited 2018 Aug 30]. [Full Text]
6. Fast Facts and FAQs. Fistula Foundation [Internet]. [Cited 2018 Aug 30]. [Full Text]

7. UN. International day to end Obstetric fistula. New York: United Nations [Internet]. [Cited 2018 Aug 30]. [Full Text]

8. Semere L, Nour NM. Obstetric fistula: Living with incontinence and shame. Rev Obstet Gynecol. 2008 Fall;1(4):193-97. [PubMed Full Text]

9. UNFPA. What is fistula? Campaign to end fistula. New York: United Nations Population Fund [Internet]. [Cited 2018 Aug 30]. [Full Text]

10. Toon K. Top three causes of Obstetric fistula. Operation fistula [Internet]. 2017 May 19. [Cited 2018 Aug 30]. [Full Text]

11. Dangal G, Thapa K, Yangzom K, Karki A. Obstetric fistula in the developing world: an agonizing tragedy. NJOG. 2013;8(2):5-15. 